\title{
Management of Congenital Cystic Dilation of Common Bile Duct in Dakar (Senegal)
}

\author{
Toure Alpha Oumar", Seck Mamadou, Thiam Ousmane, Sylla Mohamed, Ka Ibrahima, \\ Gueye Mohamadou Lamine, Seye Yacine, Sarr Ibrahima Sitor, Cisse Mamadou, Dieng Madieng \\ Department of Surgery, Cheikh Anta DIOP University, Dakar, Senegal
}

Email address:

alpha.oumar@yahoo.fr (T. A. Oumar)

${ }^{*}$ Corresponding author

\section{To cite this article:}

Toure Alpha Oumar, Seck Mamadou, Thiam Ousmane, Sylla Mohamed, Ka Ibrahima, Gueye Mohamadou Lamine, Seye Yacine, Sarr Ibrahima Sitor, Cisse Mamadou, Dieng Madieng. Management of Congenital Cystic Dilation of Common Bile Duct in Dakar (Senegal). Journal of Surgery. Vol. 7, No. 6, 2019, pp. 154-157. doi: 10.11648/j.js.20190706.11

Received: August 8, 2019; Accepted: September 27, 2019; Published: October 10, 2019

\begin{abstract}
Congenital cystic dilatation of common bile duct is a rare condition in Africa and the West. Its discovery is often fortuitous. The diagnosis is based on imagery. Our goal was to report 3 cases followed by a literature review. Three patients were received, most often for pain of the right hypochondrium. There were 2 women and 1 man aged between 16 and 27 years old. The physical examination was normal. The abdominal CT scan allowed us to diagnose a IA Todani cyst in all patients, including one degenerate. Cholecystectomy with resection of the bile duct, followed by hepatico-jejunal anastomosis on anseen-Y of Roux was performed in 2 patients. The immediate suites were simple. Histology showed inflammation on 2 operative specimen and cholangiocarcinoma on the 3rd. Choledochal DKC is a rare condition, often revealed in adults by complications. Bilio-pancreatic CT is an alternative to cholangio-MRI for its diagnosis with a type I Todani easily recognized. The treatment is surgical with a bad prognosis in case of degeneration.
\end{abstract}

Keywords: Cystic Dilatation, Bile Duct, CT Scan, MRI, Surgery

\section{Introduction}

Congenital cystic dilatation (CCD) of bile ducts is due to an abnormality of the bilio- pancreatic junction, resulting from an embryological deficit of migration of the long common biliopancreatic junction and a sphincter deficiency $[1,2]$. It is a rare pathology in Western countries and Africa, more frequent in Asia whose diagnosis is mainly based on imaging [3, 4]. Our goal was to report a 3 cases management of this pathology at the Department of General Surgery of the Dantec University Hospital in Dakar.

\section{Case Discussion}

\subsection{Case \#1}

AF, 27 years-old, was received for recurrent right-upper quadrant pain since 5 years, with fever and uncalculated weight loss. The physical examination was normal. Biological tests found a slight cytolysis with TGO at 79.6 U/L and TGP at 43.7
U/L. Total and direct bilirubin levels were 13 and $7 \mathrm{mg} / \mathrm{L}$. The abdominal ultrasound was in favor of a mixed hilar formation, and intra-vesicular hyperechogenic formations without posterior acoustic shade. Abdominal CT-scan showed a bile duct cyst type Ia of Todani without intrahepatic extension with a tumoral intra luminal bud (Figures 1 and 2).

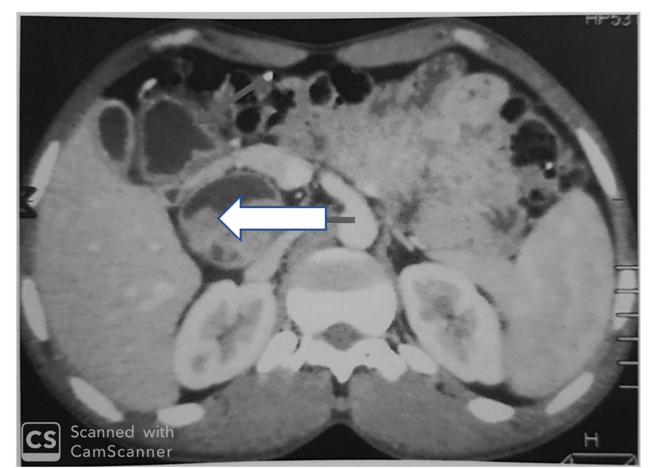

Figure 1. Common bile duct cyst with intra-luminal tumor on abdominal CT-scan (arrow). 


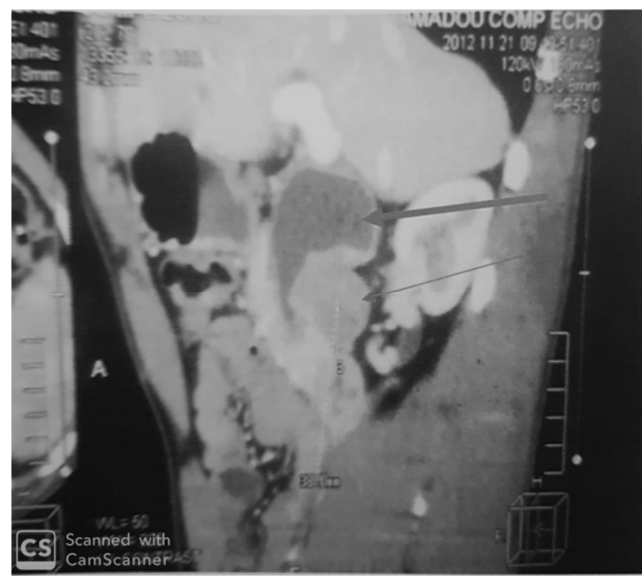

Figure 2. Sagittal view of a degenerated Choledocal cyst (Scannographic reconstruction).

Exploration by midline laparotomy revealed a tumoral process in a low bile duct cyst, without visible metastasis or carcinomatosis. We performed a cephalic duodenopancreatectomy (CDP) followed by a Child anastomosis. The postoperative courses were uneventfull with a medical discharge at $7^{\text {th }}$ postoperative day. Histological examination of the operative specimen revealed a cystadenocarcinoma of the biliary mucosa with healthy margins and 2 invaded lymph nodes. A local recurrence was observed at 1 year but the patient was lost of sight.

\subsection{Case \#2}

RSB is a 27 years-old female patient received for epigastric recurrent pain, evolving for several years. The physical examination found a sensitivity to the deep palpation of the right hypochondrium without tenderness. The blood cell count was normal. Hepatic tests were also normal (total bilirubin: $2.1 \mathrm{mg} / \mathrm{l}$, direct bilirubin: $0.6 \mathrm{mg} / \mathrm{l}$, TGO: $18.2 \mathrm{U} / \mathrm{L}, \mathrm{TGP}: 12.8 \mathrm{U} / \mathrm{L}$, alkaline phosphatase: 97,1 U/L, Gamma GT: 23 U/L). The abdominal CT-scan revealed an intra-pancreatic bile duct cyst of $22 \times 40 \mathrm{~mm}$ (Figure 3 ).

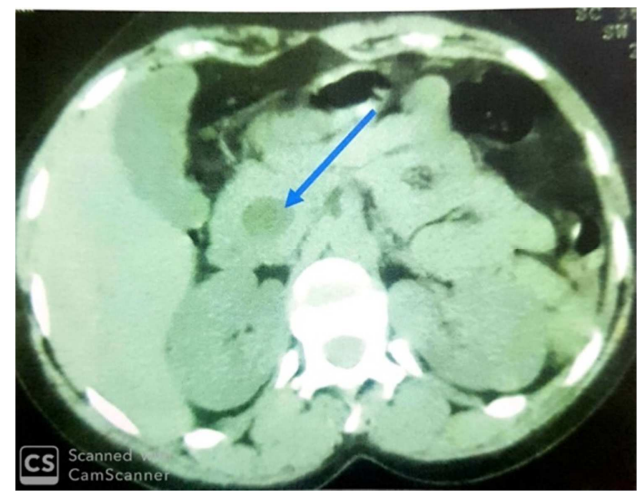

Figure 3. Scannographic view of a retro-pancreatic bile duct Cyst (arrow).

Surgical exploration had allowed us to recover a type Ia of Todani biliary cyst, without lesions in the head of the pancreas. She underwent resection of the common bile duct, cholecystectomy and an hepato-jejunal Roux anastomosis (figure 4).

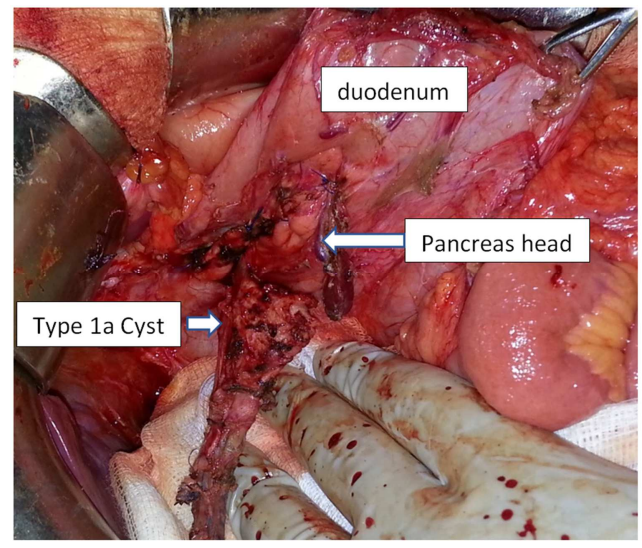

Figure 4. Type Ia Cyst of Common bile duct dissection.

The postoperative were uneventfull with medical discharge on the $8^{\text {th }}$ postoperative day. The pathological anatomy of the room revealed an inflammatory cyst of the common bile duct. The patient was diagnosed 4 years after surgery with ascending cholangitis due to hepatico-jejunal anastomosis stenosis. She underwent a second surgery with reconstruction of the anastomosis. A 1-year follow-up showed no recurrency.

\subsection{Case \#3}

$\mathrm{KD}$ is a 16-year-old patient who was diagnosed with abdominal pain since childhood in 2013, plus jaundice and vomiting 1 month before admission. Physical examination, in addition to conjunctival jaundice, was normal. Total and direct bilirubin levels were 12.7 and $11.71 \mathrm{mg} / \mathrm{dl}$. Transaminases had normal values (TGP: $24.3 \mathrm{U} / \mathrm{L}$, TGO: 23.6 U/L). CT objectified dilation of the gallbladder and bile Type Ia of Todani. There was no dilatation of the intrahepatic bile ducts (Figure 5).

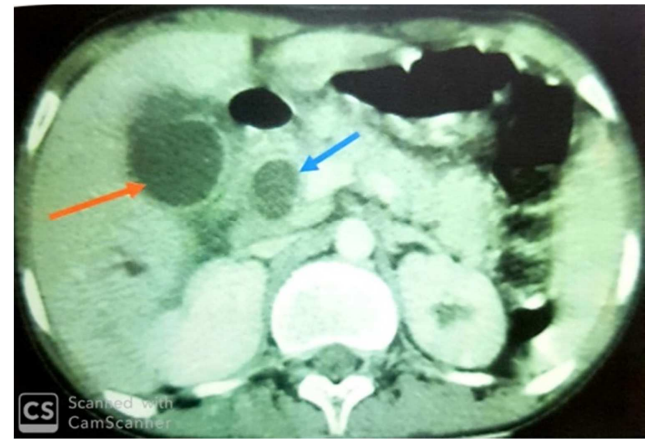

Figure 5. Gallbladder (red arrow) and choledocal cystic dilatation (blue arrow).

During surgical exploration we found a dilation compatible with a type Ia of Todani. The procedure consisted of cholecystectomy and resection of the common bile duct, followed by a Roux-en-Y hepatico- jejunal anastomosis. The postoperative course was uneventful with medical discharge on $9^{\text {th }}$ postoperative day. Examination of the operative specimen showed chronic cholecystitis and inflammation of 
the mucosa of the common bile duct.

\section{Discussion}

Cystic dilatation of the common bile duct is a rare condition in Africa and Europe, but more common in Asia. Its incidence varies from $1 / 13000$ births in Japan to $1 / 2000000$ in Europe and Africa [5-7]. Children and women are the most affected, particularly in Asia where 2/3 of cases are reported [8]. In Africa and the Western countries, it is generally discovered in adulthood, in the stage of complication as in our series $[9,10]$. The symptomatic triad, consisting of fever, abdominal pain and jaundice, is most often incomplete and found in $20 \%$ of cases [5, 11]. In our cases, the most frequent symptom was right upper quadrant pain. Non-specific biology is performed in search of cholestasis and cytolysis that may result from this condition $([9,12])$. Radiological exams are the key of diagnosis and determination of the type and associated abnormalities [12]. The abdominal CT scan, whose sensitivity in the visualization of DKC, especially of type I of Todani, is high. It allowed us to make the diagnosis in all our patients. It allows, indeed, a good characterization of the cysts, by the study of the distal portion of the common bile duct [12]. Endoscopic retrograde cholangiopancreatography (ERCP) was, for many years, the gold standard for the diagnosis of bile duct CDC and its complications [13]. It is currently supplanted by MRI. This allows a complete anatomical study of the biliary arborization by specifying the size and morphological characteristics of the choledochal cyst (sensitivity 100\%) and its possible association with an anomaly of the bilio- pancreatic junction (sensitivity of 69 to $80 \%)$ [3, 12, 14-16]. In our work conditions, with the difficulty of access to these 2 exams, CT scan was sufficient to make the diagnosis of DKC.

The treatment is essentially surgical as it was the case for all our patients. It must be radical, associating a cholecystectomy and a complete resection of the cyst because of the risk of degeneration of its mucosa. It is completed by a Roux-en-Y hepatico- jejunal anastomosis for better drainage $[17,18]$. The cephalic duodeno-pancreatectomy is a procedure rarely practiced and reserved for cases of degenerated intra-pancreatic cyst or invasion of the pancreas [19]. Non-invasive treatments, such as endoscopic sphincterotomy, percutaneous biliary drainage, are wait-andsee solutions to surgery, which, well conducted, offers excellent long-term results $[12,20]$. Cholangitis is the most common postoperative complication (approximately 11\%) and is thought to be due to insufficient clearance of biliodigestive anastomosis. After histology of the operative specimen, inflammatory pathology, due to a permanent reflux of pancreatic secretion, is more frequent as seen in 2 of our patients [21]. Tumor development increases from $1 \%$ to $14 \%$ from childhood to adulthood [5]. The incidence of cholangiocarcinoma, which has a bad prognosis, is 20 to 30 times higher in the case of bile ducts CDC than in the general population, and even more so in the case of type I $[18,22]$.
The only case of degenerated bile duct cyst we had had a tumor recurrence one year after surgery.

\section{Conclusion}

Choledochal CCD is a rare condition, often childly discovered or at complicated stage for adults. The symptoms are not very specific. That is why its diagnosis is based on imaging including CT-scan and cholangio-pancreatic MRI. Due to the pancreatic reflux in the common bile duct, cancer risk is high. So treatment must be aggressive. It is based on surgery, like complete resection of the common bile duct with hepatico-jejunal anastomosis wich has good results.

\section{Recommandations}

These cases show us that surgeons must have some degree of clinical suspicion in order to make the appropriate diagnostic by using CT-scan, or better, MRI and to facilitate appropriate treatment of choledochal cysts.

\section{Author Contributions}

All authors contributed equally in collecting datas, analyzing and writing this paper.

\section{Conflict of Interest Statement}

Authors declare no competing interest.

\section{References}

[1] Rayya F, Balouli M, AlshaikhaY. Congenital common bile duct cyst. J Ped Surg Case Reports 2019, 43: 8-10.

[2] Khmekhem H, Zitouni H, Ben Ahmed Y, Jlidi S, Nouira F, Charleg A et al. traitement chirurgical des dilatations kystiques de la voie biliaire chez l'enfant. Résultats à propos de 16 observations. J Ped Puericult 2012; 25: 199-205.

[3] Disibeyaz S, Parlak E, Cicek B, Cengiz C, Kuran SO, Oguz D et al. Anomalous opening of the common bile duct into the duodenal bulb: endoscopic treatment. BMC Gastroenterol 2007; 7: 26.

[4] Bricha M, Dafiri R. Une cause inhabituelle d'un abdomen aigu chez l'enfant: la rupture spontanée d'un kyste du cholédoque. J Radiol 2007; 88: 692-693.

[5] Kamisawa T, kaneko K, Itoi T, Ando H. Pancreaticobiliary maljunction and congenital biliary dilatation. Lancet Gastroenterol Hepatol 2017; 2: 610-18.

[6] Pilleul F. Asymptomatic or paucisymptomatic common bile duct dilatation on ultra-sonography after cholecystectomy: management. J Radiol 2006; 2 (1): 41-44.

[7] Savic Dj, Milovanovic D, Jovanovic D. Congenital dilatation of the common bile duct. Srp Arh Celok Lek 2001; 129 (1): 47-50. 
[8] Elabsi M, Amraoui M, Elouannani M, Echarrab M, Elalami FA, Errougani A et al. Dilatation kystique du colédoque associée à une dilatation kystique du canal cystique. J Chir 2006; 146 (5): 308-309.

[9] Croome KP, Nagorney DM. Chapter 46: Bile duct cysts in adults. Blumgart's Surgery of the Liver, Biliary Tract and Pancreas, 2-Volume Set (Sixth Edition), 2017: 752-764. e3

[10] Ka O, Dieng M, Konaté I, Ba PA, Ndongo S, Mbengue M et al. Kyste congenital du cholédoque de l'adulte: à propos de 2 observations. Dakar Med 2005, 50 (3): 128-130.

[11] Giani L, Nobili P, Annolfi B, Origgi C. Cystic dilatation of the common bile duct. G Chir 1996, 17 (1-2): 23-27.

[12] Cannela R, Giambelluca D, Diamarco M, Caruana G, Cutaia G, Midiri M et al. Congenital Cystic Lesions of the Bile Ducts: Imaging-Based Diagnosis. Current Problems in Diagnostic Radiology 2019 doi.org/10.1067/j.cpradiol.2019.04.005

[13] DagherI, Franco D. Lésions kystiques du foie et des voies biliaires (en dehors du kyste hydatique). Place de la chirurgie. Gastroenterol Clin Biol 2005; 29: 875-877.

[14] Moslim MA, Takahashi H, Seifarth FG, Walsh RM, MorrisStiff G. Choledochal cyst disease in a western center: a 30year experience. J Gastrointest. 2016, 8: 1453-1463.

[15] Dostalik J, Gunka I, Martink L, Cernoch J, Mazur M. A case report of a 39 years-old male with choledochal cyst mimicking pancreatic pseudocyst. Hepatogastroenterology 2007; 54 (74): 393-396.

[16] Mantas D, Stamopoulos P, Kouskos E, Dimitroulis D. Giant biliary cyst. J. Gastrointest. Surg. 2016, 20 (10): 1778-1780.

[17] Lira AKM, Soto AJM, Frigerio P. Choledochal cyst Todani IA case report. Int J Surg Case reports 2016, 28: 293-295.

[18] Nguyen Galvàn NT, Kumm K, Yoeli D, Witte E, Kueht M, Cotton RT et al. An impressive choledochal cyst and its surgical resection. Int J Surg Case Reports 2017, 33: 48-50.

[19] Vullierme MP, Vilgrain V, Zins M, Sibert A, Denys A, Belghiti $\mathrm{J}$ et al. Dilatation kystique congénitale de la voie biliaire principale: corrélations radio-anatomiques chez 14 malades. Gastroenterol Clin Biol 1997; 21: 201-208.

[20] Kamisawa T, Ando H, Suyama M, et al, for the Japanese Study Group on Pancreaticobiliary Maljunction. Japanese clinical practice guidelines for pancreaticobiliary maljunction. J Gastroenterol 2012; 47: 731-59.

[21] Soares KC, Kim Y, Spolverato G, et al. Presentation and clinical outcomes of 'choledochal cysts in children and adults: a multi-institutional analysis. JAMA Surg 2015, 150: 577584 .

[22] Le Bail B. Pathologie de la vésicule biliaire te des voies biliaires extra-hépatiques. Introduction. Ann Path 2014; 34: 258-265. 